\title{
Interaction between a Side Chain Crystalline Block Copolymer and Wax
}

\author{
Tateishi $\mathbf{Y}^{1}$, Takase $\mathbf{Y}^{1}$, Yoda $\mathbf{K}^{2}$, Nakano $\mathrm{R}^{1}$, Sekiguchi $\mathbf{H}^{1}$ and Yao \\ $S^{1,3 *}$ \\ ${ }^{1}$ Department of Chemical Engineering, Faculty of Engineering, Fukuoka University, \\ Japan
}

${ }^{2}$ R\&D Development Research Makeup Products Research Kao Corporation 5-3-28

\section{Research Article}

Volume 2 Issue 7

Received Date: October 15, 2018

Published Date: October 26, 2018

DOI: $10.23880 /$ ppej-16000174

Kotobukicho, Japan

${ }^{3}$ Department of Chemical Engineering, Graduate School of Engineering, Fukuoka University, Japan

*Corresponding author: Shigeru Yao, Department of Chemical Engineering, Graduate School of Engineering, Fukuoka University, 8-19-1 Nanakuma, Jonan-ku, Fukuoka 814-0180, Japan, Tel: +81-92-871-6631; Email: shyao@fukuoka-u.ac.jp

\section{Abstract}

To solve these issues, the use of various additives has been proposed. In recent years, we have synthesized a block copolymer of acrylate monomers with long alkyl side chain and solvophilic monomers. The SCCBC, in particular, exerts a very remarkable dispersant effect for a concentrated PE particle dispersion. In this study, we have investigated the influence of the addition of the SCCBC on the crystallization of model wax/oil mixtures, and the temperature dependence on its rheological properties. Examination of the temperature dependence of viscosity or viscoelasticity revealed that the addition of SCCBC prevents the wax/oil mixed system from losing fluidity, even at the low temperatures at which wax would normally solidify. The non-solidification and fluidization effects of the model wax/oil mixed system, described herein, will be helpful in reducing blockages in pipelines for crude oil and in reducing the accumulation of sludge at the bottom of oil storage tanks.

Keywords: Side chain crystalline block copolymer; Crystalline supramolecular interaction; Non-solidification effect; Fluidization effect

\section{Introduction}

Petroleum has the property that as the ambient temperature decreases, wax contained within precipitates out. The temperature at which this precipitation of wax begins is called the pour point temperature (PPT). It is an index which indicates an important physical property of petroleum. This phenomenon causes a reduction in the effective diameter of pipelines used for the transport of crude oil, and can result in the blockage of pipelines, particularly in cold climate areas. Consequently, developing a means to efficiently detect blockages within pipeline networks, and exchange the blocked sections, is a 


\section{Petroleum \& Petrochemical Engineering Journal}

very economically significant issue. Various techniques for the issue have been considered [1-3], but the issue has yet to be solved. A further issue is that, sludge accumulates at the bottom of petroleum storage tanks. Therefore, the tanks regularly have to be manually emptied and cleaned in order to remove the sludge. This work is extremely dangerous, as fires and fatal accidents have frequently occurred. This issue also shows that the solidification of wax from petroleum is very important problem [4,5]. To solve these issues, the use of various additives has been proposed. In recent years, many reports have suggested that acrylates with long alkyl side chains show a good dispersant effect $[6,7]$. Copolymers of acrylate monomers with long alkyl side chains and other monomers have also been reported to produce good results $[8,9]$.

In recent years, we have synthesized a block copolymer of acrylate monomers with long alkyl side chain and solvophilic monomers. Due to its long alkyl side chains, the side chain moiety of this block copolymer crystallizes. We have thus called it as a "side chain crystalline block copolymer" (SCCBC). We have also found that this block copolymer interacts with polyethylene (PE) by crystalline supramolecular interaction and that it shows a strong adhesive interaction with PE. This block copolymer, in particular, exerts a very remarkable dispersant effect for a concentrated PE particle dispersion [10-20]. In this study, we have investigated the influence of the addition of this block copolymer on the crystallization of model wax/oil mixtures, and the temperature dependence on its rheological properties.

\section{Experiments}

\section{Polymerization of A Side Chain Crystalline Block Copolymer}

Behenyl acrylate (BHA) was used as a side-chain crystalline monomer, and n-butyl acrylate (n-BA) as a functional monomer. The polymerization of SCCBC was performed by living radical polymerization (nitroxidemediated polymerization (NMP)) at $110^{\circ} \mathrm{C}$ in an atmosphere of nitrogen. A BlocBuilder-MA ${ }^{\circledR}$ (Arkema) was used as an initiator. The side-chain crystalline monomer was polymerized first, and n-BA was then successively added to the reaction system after the elapse of a predetermined time period. The total weight-average molecular weight $(\mathrm{Mw})$ of the polymerized block copolymer was $13000 \mathrm{~g} / \mathrm{mol}$ (the Mw of a BHA unit is $6000 \mathrm{~g} / \mathrm{mol}$ and the Mw of an $\mathrm{n}-\mathrm{BA}$ unit is $7000 \mathrm{~g} / \mathrm{mol}$ ).
Figure 1 shows the chemical structure of the polymerized SCCBC.

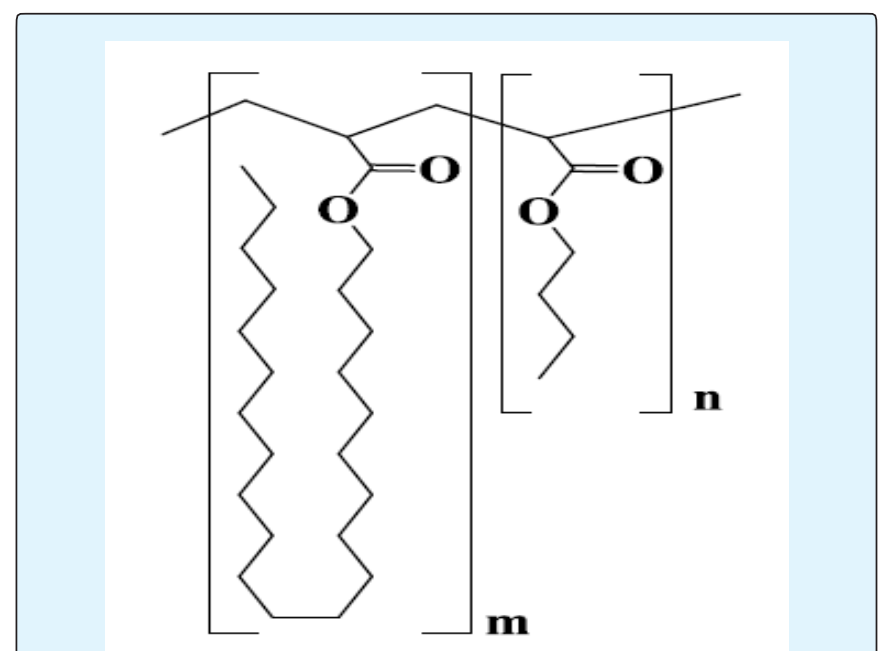

Figure 1: Schematic Chemical Structure of SCCBC.

\section{Preparation of the WAX/Oil Mixed System}

A model wax-dispersed system was used as a base system in this study. It consists of a mixture of ceresin wax and isotridecyl isononanoate (oil) in a ratio of 20:80. Ceresin wax and isotridecyl isononanoate were melted once and mixed, following which they were cooled to solidify. SCCBC was added to the base system, until it had a content of either $0.1 \mathrm{wt} \%$ or $0.5 \mathrm{wt} \%$ relative to the wax.

\section{Measurements}

\section{Viscosity and Viscoelastic Properties}

To estimate the temperature dependence of viscosity and dynamic viscoelastic properties of each waxdispersed systems, we conducted steady flow viscosity measurements and dynamic measurements using a coneplate rheometer (cone diameter: $39.97 \mathrm{~mm}$, cone angle: $2.009^{\circ}$ ). For these measurements, the shear rate was $0.020-100 \mathrm{sec}^{-1}$, the frequency was $0.01-10 \mathrm{radsec}^{-1}$, and a series of temperatures were used; $25,40,50,60,70$, and $80^{\circ} \mathrm{C}$.

\section{Polarizing Microscope Observations}

To investigate the temperature dependence of the crystal structure, we used a polarizing microscope with a hot stage. The structure of the crystals was observed at both the normal temperature $\left(35^{\circ} \mathrm{C}\right)$, and in a molten state $\left(90^{\circ} \mathrm{C}\right)$. 


\section{Petroleum \& Petrochemical Engineering Journal}

\section{DSC Measurements}

To investigate the melting behavior of each waxdispersed system, we measured the melting temperature and heat of fusion using a differential scanning calorimeter (DSC, PerkinElmer DSC8500).

\section{Results and Discussion}

Figure 2 shows microscopic images of the wax/oil mixed systems without SCCBC, with $0.1 \mathrm{wt} \%$ of SCCBC, and with $0.5 \mathrm{wt} \%$ of SCCBC. Each systems are shown at $35^{\circ} \mathrm{C}$ and $90^{\circ} \mathrm{C}$. These images were taken using a polarizing microscope. In the comparison of images at $35^{\circ} \mathrm{C}$ demonstrates that while spherical crystals about 10 $\mu \mathrm{m}$ in diameter are found in the wax/oil mixed system without SCCBC system, as shown in Figure 2 (a), very fine needle-like looks crystals about $5 \mu \mathrm{m}$ wide and $20 \mu \mathrm{m}$ long are found in the wax/oil mixed system with $0.1 \mathrm{wt} \%$ of SCCBC system, as shown in Figure 2 (b). Furthermore, larger, needle-like looks crystals about $10 \mu \mathrm{m}$ wide and 50 $\mu \mathrm{m}$ long are found in the wax/oil mixed system with 0.5 wt $\%$ of SCCBC system, as shown in Figure 2(c).

Images at $90^{\circ} \mathrm{C}$ show that wax crystals were completely melted in both the wax/oil mixed system without SCCBC, and in the $0.1 \mathrm{wt} \%$ system, as shown in Figures 2(d) and 2(e), respectively. However, microcrystals remained in the wax/oil mixed system with 0.5 wt $\%$ of SCCBC, as shown in Figure 2 (f). This result suggests the possibility that there is an increase in the melting point of the crystals, due to strong interactions between the side-chain crystalline moieties of SCCBC and wax.

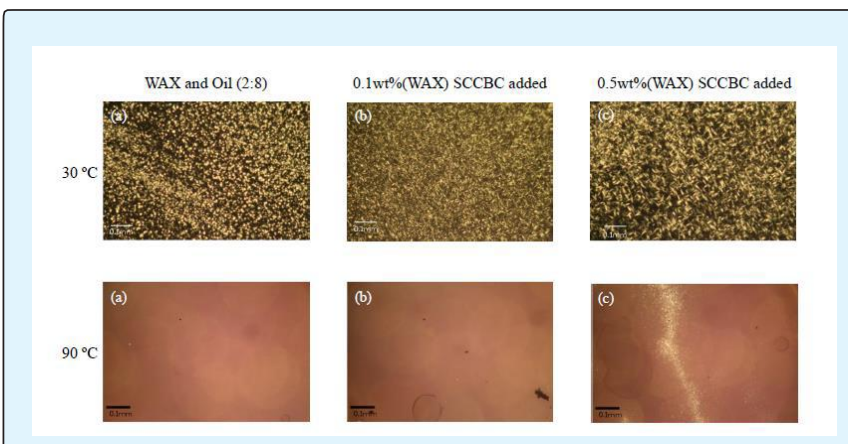

Figure 2: Temperature dependence of the crystal structure of SCCBC/WAX and Oil observed by Polarizing microscope. Upper line images are at $30^{\circ} \mathrm{C}$ and lower line images are at $90^{\circ} \mathrm{C}$. (a): Original WAX and Oil system, (b): $0.1 w t \%$ SCCBC added to original system, (c): $0.5 \mathrm{wt} \%$ SCCBC added to original system.

Figure 3 shows DSC profiles for the wax/oil mixed system both without SCCBC, and with $0.5 \mathrm{wt} \%$. This indicates that while the wax/oil mixed system without SCCBC has a melting peak for wax at about $55^{\circ} \mathrm{C}$, this is $2^{\circ} \mathrm{C}$ lower in the system with $0.5 \mathrm{wt} \%$ of SCCBC, where the melting peak occurs at $57^{\circ} \mathrm{C}$. The wax/oil mixed system with $0.5 \mathrm{wt} \%$ of SCCBC also shows a distinctive profile, in which a sharp endothermic peak. The heat of fusion in the $0.5 \mathrm{wt} \%$ system is larger than that in the system without SCCBC. These results indicate that the system with 0.5 $\mathrm{wt} \%$ of SCCBC becomes harder to melt. These findings suggest that SCCBC works as a nucleating agent for the crystallization of the wax.
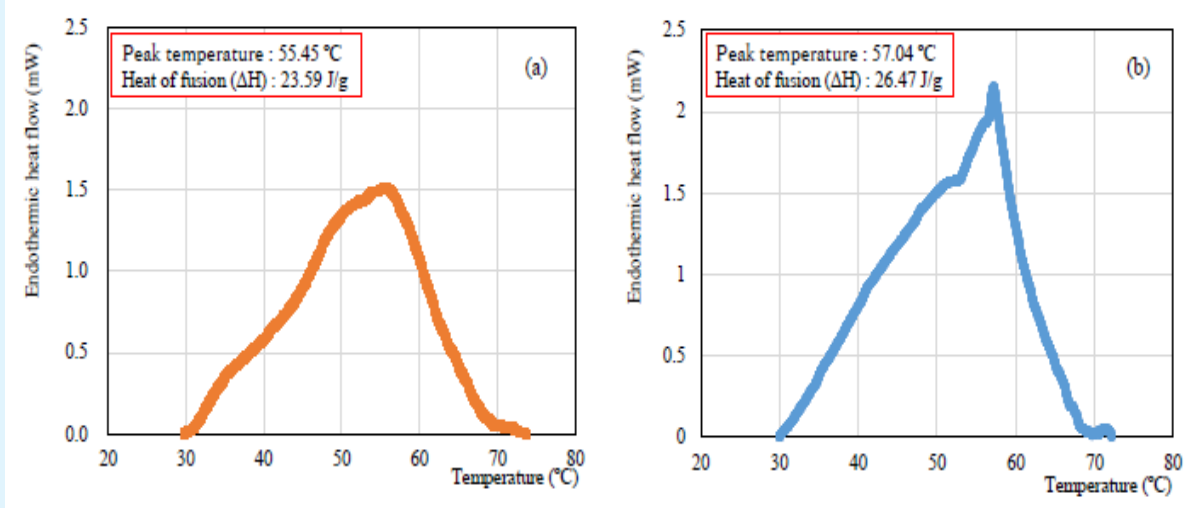

Figure 3: DSC profiles of (a): Original WAX and Oil system and (b): $0.5 \mathrm{wt} \%$ SCCBC added to original system.

Yao S, et al. Interaction between a Side Chain Crystalline Block Copolymer and Wax. Pet Petro Chem Eng J 2018, 2(7): 000174. 


\section{Petroleum \& Petrochemical Engineering Journal}

In each square, values of peak temperature and heat of fusion are written. Past studies have shown that the sidechain crystalline moiety of SCCBC has a good adsorptive interaction with crystals on the surface of PE. Our results suggest the possibility that this adsorptive interaction is produced by the formation of pseudo-crystals between alkyl chains of the side-chain crystalline moiety of SCCBC, and the relatively loose crystals of the polymer chains on the PE surface.
Figure 4 shows the shear rate and temperature dependence of the shear viscosity of the wax/oil mixed system, both without SCCBC and with $0.5 \mathrm{wt} \%$ SCCBC. The system without SCCBC is shown in Figure 4 (a). In the temperature range above $60^{\circ} \mathrm{C}$, which is also higher than the melting point obtained from the results of the DSC, the viscosity is so low that the response stress is below the limit of the measurement equipment in the low shear rate range. The system behaves as a Newtonian fluid in this range.
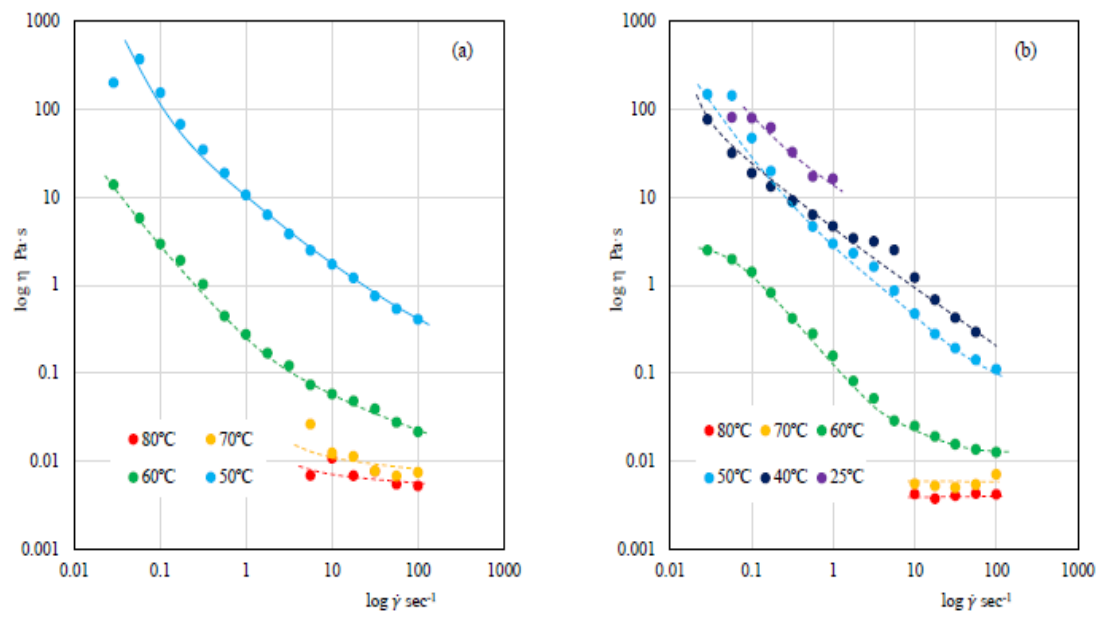

Figure 4: Temperature and shear rate dependence of shear viscosity. (a): Original WAX and Oil system and (b): $0.5 \mathrm{wt} \%$ SCCBC added to original system.

In the temperature range lower than $60^{\circ} \mathrm{C}$, the viscosities are found to depend on the temperature, and increase greatly. The viscosities also show shear rate dependence and greatly increase in the low shear rate range. Here the systems change to a non-Newtonian fluid, which show yield values. Below $50^{\circ} \mathrm{C}$, it was impossible to conduct the measurement because the samples completely solidified, and slipped off the jigs.

The system with 0.5 wt $\%$ of SCCBC, shown in Figure 4 (b) exhibited different properties. In the temperature range higher than $60^{\circ} \mathrm{C}$, the viscosities are as low as, or equal to that of the system without SCCBC. The systems show the behavior of a Newtonian fluid, which do not depend on the shear rate. In the temperature range lower than $60^{\circ} \mathrm{C}$, the viscosities depend on the shear rate and the systems have yield values in the low shear rate range. The viscosity in this systems are slightly lower than in that without SCCBC. Furthermore, although the viscosity greatly increased, the temperature dependence is very small in the temperature range lower than $50^{\circ} \mathrm{C}$. From the measurement, the shear viscosity could be measured successfully until the temperature reached $25^{\circ} \mathrm{C}$. Consequently, the addition of SCCBC can be seen to give the wax/oil mixed system fluidity in the lower temperature range.

Figure 5 shows the frequency dependence of the storage modulus $\left(\mathrm{G}^{\prime}\right)$ in dynamic measurement, of the wax/oil mixed systems without and with SCCBC. Figure 5 (a) shows that in the range higher than $60^{\circ} \mathrm{C}, \mathrm{G}^{\prime}$ shows dependence almost with the square of the frequency, and the system seems to be in the relaxation state. Below $60^{\circ} \mathrm{C}$, the system can be considered to be in the solid or crystalline state, because frequency dependence disappeared. Also in this case, it was impossible to conduct the measurements below $50^{\circ} \mathrm{C}$, because the sample slipped off jigs. Conversely, the wax/oil mixed system with SCCBC, shown in Figure 5 (b), exhibits a good fluidity in the temperature range from $60^{\circ} \mathrm{C}$ to $80^{\circ} \mathrm{C}$, and 


\section{Petroleum \& Petrochemical Engineering Journal}

the temperature range in which it has fluidity is found to shift toward the lower temperatures. Below $50^{\circ} \mathrm{C}$, although $G^{\prime}$ loses frequency dependence, the measurement was conducted successfully until the temperature reached $25^{\circ} \mathrm{C}$. This indicates that the influence of solidification of the wax did not appear in all parts of the system.
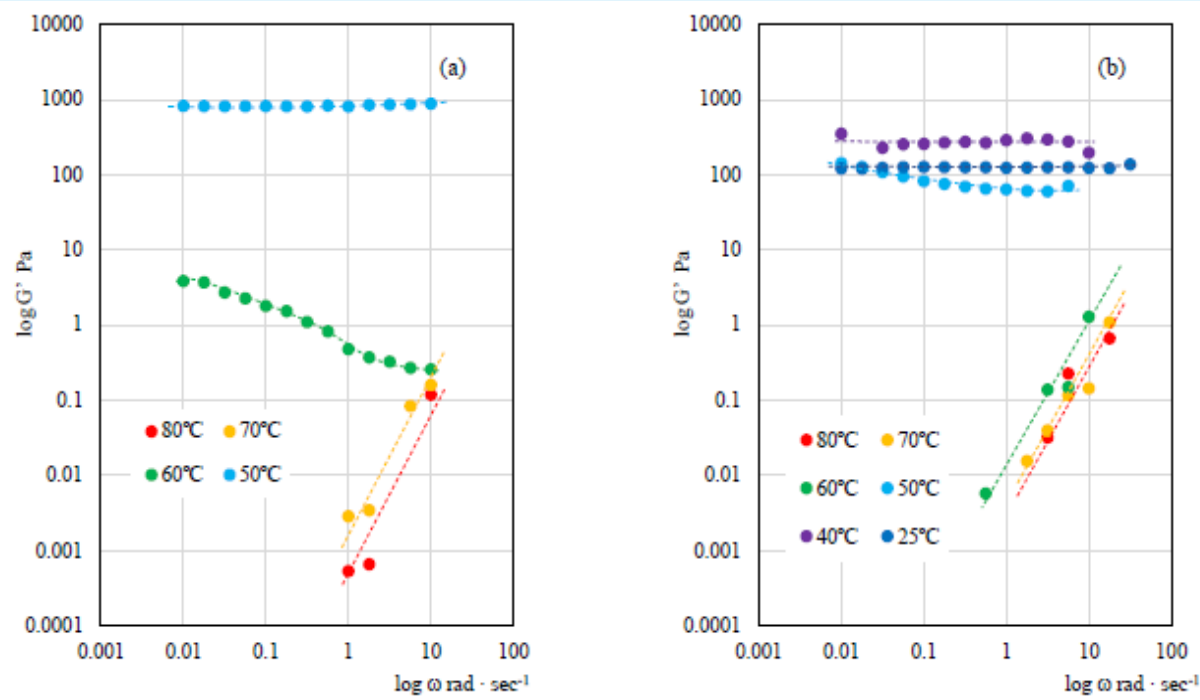

Figure 5: Temperature and frequency dependence of storage modulus. (a): Original WAX and Oil system and (b): $0.5 \mathrm{wt} \%$ SCCBC added to original system.

Figure 6 shows the frequency dependence of dynamic viscosity $\left(\left|\eta^{*}\right|\right)$. The results for the wax/oil mixed system shown in Figures 6 (a) and 6 (b) demonstrate almost the same tendencies as the results for $\mathrm{G}^{\prime}$.
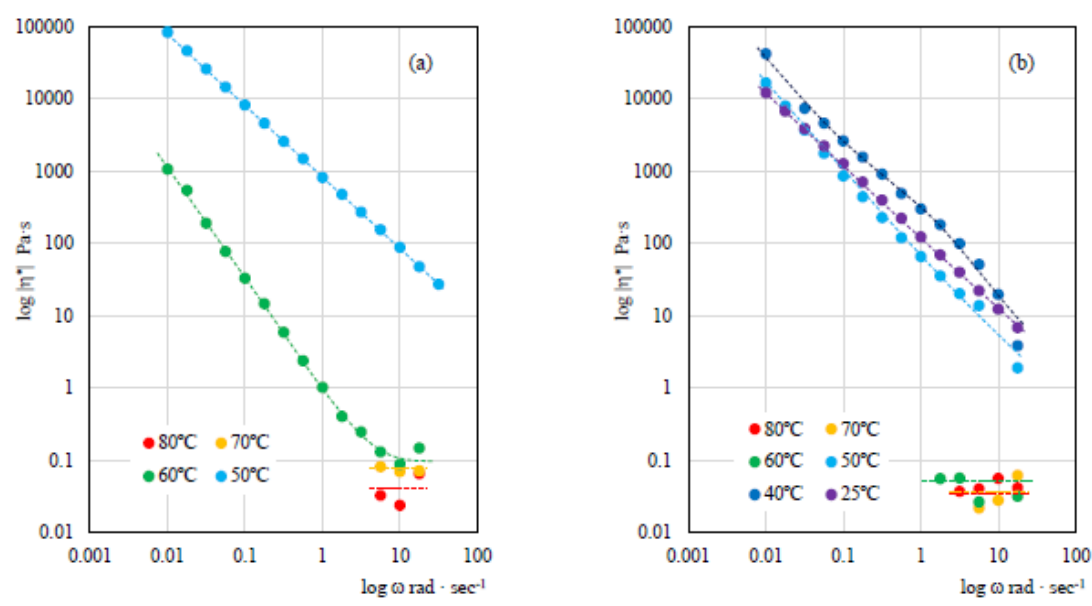

Figure 6: Temperature and frequency dependence of complex viscosity. (a): Original WAX and Oil system and (b): $0.5 w t \%$ SCCBC added to original system. 


\section{Petroleum \& Petrochemical Engineering Journal}

Figure 7 shows the temperature dependence of the shear viscosity at $1 \mathrm{sec}^{-1}$ of the shear rate. This suggests that the viscosity of the system without SCCBC diverged infinitely and the fluidity was suddenly lost under $60^{\circ} \mathrm{C}$. However, the system with SCCBC exhibited this fluidity even under $50^{\circ} \mathrm{C}$ and the viscosity remained at an almost constant value.

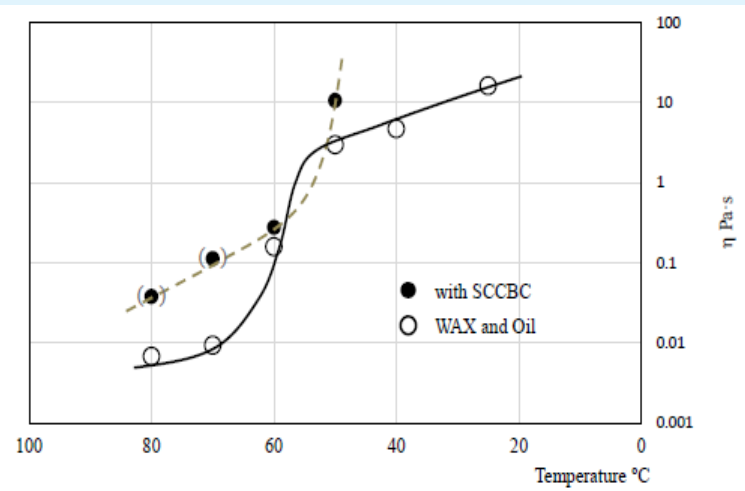

Figure 7: Temperature dependence of shear viscosity at $1 \mathrm{sec}^{-1}$. Closed circles and break line: Original WAX and Oil system, Open circles and line: 0.5wt\% SCCBC added to original system.

Figure 8 shows the temperature dependence of $\mathrm{G}^{\prime}$ and $\left|\eta^{*}\right|$ at $1 \mathrm{radsec}^{-1}$ of the frequency. These figures show that while the $\mathrm{G}^{\prime}$ and $\left|\eta^{*}\right|$ of the wax/oil mixed system without SCCBC diverged infinitely, the $G^{\prime}$ and $\left|\eta^{*}\right|$ of the system with SCCBC was successfully measured until the temperature reached $25^{\circ} \mathrm{C}$. It converged at an almost constant value. Figure 9 shows the external appearance of the wax/oil mixed systems without and with SCCBC at normal temperatures. In the case of the wax/oil mixed system without SCCBC, shown in Figure 9 (a), dry wax crystals are observed and oil that is supposed to make up $80 \mathrm{wt} \%$ of the system, however, does not appear on the surface. In contrast, the surface of the wax/oil mixed system with SCCBC is glossy and wetted with oil. Lower illustrates represent these states schematically. In the case of the wax/oil mixed system without SCCBC, shown in left side, the oil is contained in the aggregated structure formed by wax crystals. The system solidifies as the wax crystals come into contact with each other. As a result, the surface of the system is seemingly dry. In addition, it is considered that the formation of such a structure causes a sudden loss of fluidity at low temperatures. Conversely, in the case of the wax/oil mixed system with SCCBC, shown in right side, SCCBC adsorbs onto wax crystals and the lipophilic moieties of SCCBC cover the wax crystals, like brushes. As a result, the oil wettability of the wax crystals is enhanced, causing the oil to localize around the wax crystals and hinder the crystals from making direct contact with each other. Consequently, the surface of the system is seemingly wetted, and the fluidity is retained even at a low temperature.
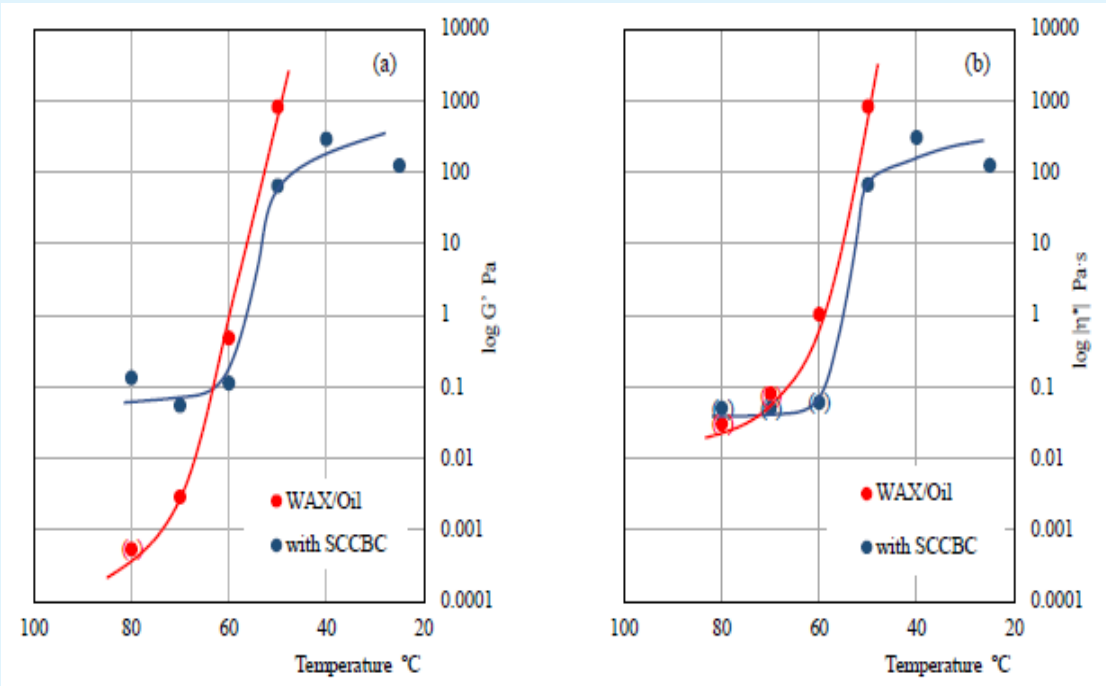

Figure 8: Temperature dependence of storage modulus (a) and complex viscosity (b) at $1 \mathrm{rad}^{\circ} \mathrm{sec}^{-1}$. Blue marks and line: Original WAX and Oil system, Red marks and line: $0.5 \mathrm{wt} \%$ SCCBC added to original system. 


\section{Petroleum \& Petrochemical Engineering Journal}

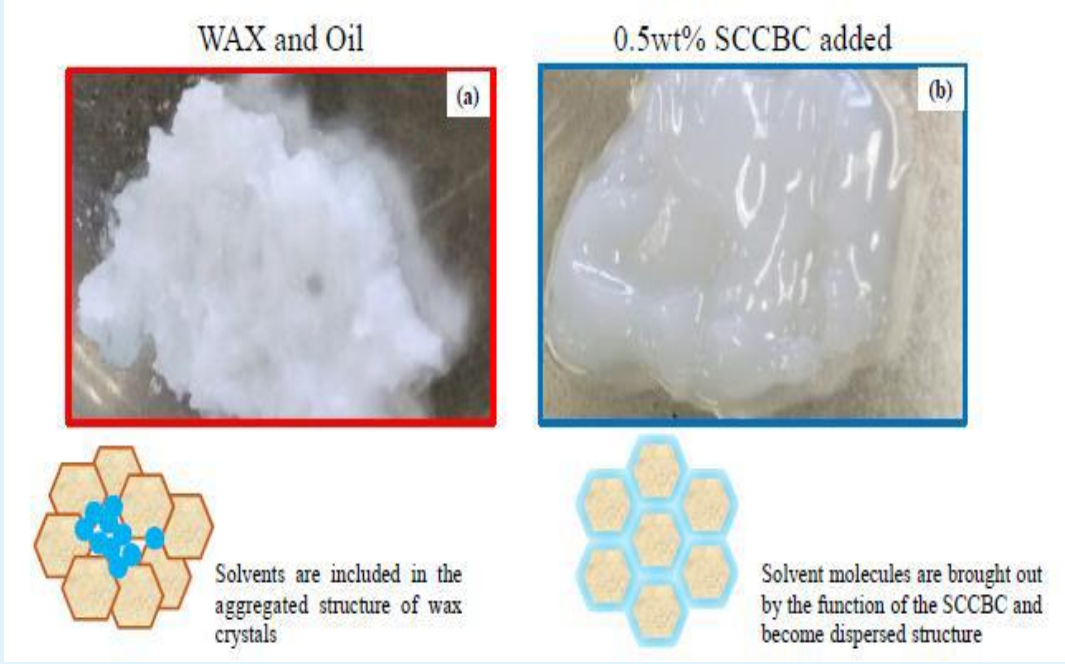

Figure 9: Out looks of the samples at 35ํㅡ. (a): Original WAX and Oil system, (b): $0.5 w t \%$ SCCBC added to original system. Lower illustrates are schematic image of each wax crystal and oil structure.

\section{Conclusion}

In this study, we examined the effect of the addition of SCCBC to model wax/oil mixed systems. The addition of SCCBC caused changes in wax crystal morphology. The reason for this is that the crystalline moieties of SCCBC work as a nucleating agent for the crystallization of wax. Meanwhile, examination of the temperature dependence of viscosity or viscoelasticity revealed that the addition of SCCBC prevents the wax/oil mixed system from losing fluidity, even at the low temperatures at which wax would normally solidify. The reason for this is as follows: After the adsorption of SCCBC onto wax crystals, solvophilic moieties of SCCBC grow on the surface of the wax crystals, like brushes. Then, the solvent localizes around the surface of the wax crystals and hinders them from making direct contact with each other. As a result, the fluidity of the wetting layer on the surface is retained. The nonsolidification and fluidization effects of the model wax/oil mixed system, described herein, will be helpful in reducing blockages in pipelines for crude oil and in reducing the accumulation of sludge at the bottom of oil storage tanks.

\section{References}

1. Bocchini P, Marzani A, Karamlou A (2014) Shale Energy Engineering Conference, pp: 676.
2. Wang XJ, Lambert MF, Simpson AR (2004) World Water and Environmental Resources Congress 2004.

3. Vidal JA, Silva LL, Netto TA, Monteiro PCCJ (2014) Proceedings of the 33th International Conference on Ocean, Offshore and Arctic Engineering (OMAE 2014).

4. Yamaguma M, Mizutani T, Shimada Y (2011) A Study on the Cause of the Fire in a Crude-oil Tank during Cleaning. Journal of Japan Society for Safety Engineering 50(2): 101-107.

5. Hu G, Li J, Zeng G (2013) Recent development in the treatment of oily sludge from petroleum industry: A review. Journal of Hazardous Materials 261: 470-490.

6. El-Gamal IM, Atta AM, Al-Sabbagh AM (1997) Polymeric structures as cold flow improvers for waxy residual fuel oil. Fuel 76(14-15): 1471-1478.

7. Wei BJ (2015) Recent advances on mitigating wax problem using polymeric wax crystal modifier. Journal of Petroleum Exploration and Production Technology 5(4): 391-401.

8. Atta AM, El-Ghazawy RA, Morsy FA, Hebishy AS, Elmorsy A (2015) Adsorption of Polymeric Additives Based on Vinyl Acetate Copolymers as Wax Dispersant and Its Relevance to Polymer Crystallization Mechanisms. J Chemistry 2015: 8. 


\section{Petroleum \& Petrochemical Engineering Journal}

9. Theyab MA, Diaz P (2017) Experimental Study of the Effect of Polyacrylate Polymer (C16-C22) on Wax Deposition. International Journal of Chemical Engineering and Applications 8(1): 16.

10. Yao S, Ichikawa SA (2011) Novel Dispersant for High Content Polyethylene Particle Dispersion Nihon Reoroji Gakkaishi 39(4): 181-182.

11. Ichikawa S, Yao S (2012) Thermal Rheological Properties of the Particle Dispersion Systems with Using Side Chain Crystalline Block Co-Polymer (II). Nihon Reoroji Gakkaishi 40(1): 37-40.

12. Yao S, Sekiguchi H, Ichikawa S, Tatsumi D, Sakurai M, et al. (2012) The Intelligent Material Function of Side Chain Crystalline Block Copolymer (IV). Control the Lithium Ion Mobility in Polyethylene Porous Membrane. Nihon Reoroji Gakkaishi 40(5): 253-256.

13. Okuma T, Nakano R, Sekiguchi H, Yao $\mathrm{S}$, Ichikawa $\mathrm{S}$, et al. (2013) Supramolecular function of side chain crystalline block copolymer. IEICE Technical Report 113(167): 81-82.

14. Yao S, Sakurai M, Sekiguchi H, Otsubo H, Uto T, et al. (2013) Thermal Rheological Fluid Properties of Particle Dispersion Systems using Side Chain
Crystalline Block Copolymer III. Nihon Reoroji Gakkaishi 41(1): 7-12.

15. Yao S, Okuma T, Kumamaru C, Sekiguchi H, Ichikawa S, et al. (2013) Materials Transactions 54(8): 13811384.

16. Okuma T, Nakano R, Sekiguchi H, Yao S (2014) Proceedings of the 9th JFPS International Symposium on Fluid Power.

17. Ekoko GB, Kanza Lobo JK, Mvele OM, Muswema JL, Yamambe JF (2014) International Journal of Materials Science and Applications 3(6): 339-343.

18. Nakano R, Sekiguchi H, Yao S (2015) Polyethylene Surface Modification by Side Chain Crystalline Block Copolymer. Macromolecular Symposia 349(1): 44-50.

19. Yao S (2016) Crystalline Supramolecular Interaction of Side Chain Crystalline Polymer and their Future Japanese Journal of Polymer Science and Technology 73(2): 139-146.

20. Hasebe Y, Kanazawa Y, Nakano R, Sekiguchi H, Yao S (2017) Proceedings of the 10th JFPS International Symposium on Fluid Power.

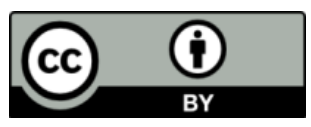

Yao S, et al. Interaction between a Side Chain Crystalline Block Copolymer and Wax. Pet Petro Chem Eng J 2018, 2(7): 000174. 